\title{
Article
}

\section{Emotions and support needs following a distressing birth: Scoping study with pregnant multigravida women in North West England}

Thomson, Gillian and Downe, Soo

Available at http://clok.uclan.ac.uk/14796/

Thomson, Gillian ORCID: 0000-0003-3392-8182 and Downe, Soo ORCID: 00000003-2848-2550 (2016) Emotions and support needs following a distressing birth: Scoping study with pregnant multigravida women in North West England. Midwifery, 40 . pp. 32-39. ISSN 0266-6138

It is advisable to refer to the publisher's version if you intend to cite from the work. http://dx.doi.org/10.1016/j.midw.2016.06.010

For more information about UCLan's research in this area go to http://www.uclan.ac.uk/researchgroups/ and search for <name of research Group>.

For information about Research generally at UCLan please go to http://www.uclan.ac.uk/research/

All outputs in CLoK are protected by Intellectual Property Rights law, including Copyright law. Copyright, IPR and Moral Rights for the works on this site are retained by the individual authors and/or other copyright owners. Terms and conditions for use of this material are defined in the policies page. 
Title: Emotions and support needs following a distressing birth: Scoping study with pregnant multigravida women in North West England

Authors: Gill Thomson ${ }^{1} \&$ Soo Downe ${ }^{2}$

${ }^{1}$ Maternal and Infant Nutrition \& Nurture Unit (MAINN), University of Central Lancashire, Preston, Lancashire. PR1 2HE. Email: gthomson@uclan.ac.uk.

${ }^{2}$ Research in Childbirth and Health Unit (ReaCH), University of Central Lancashire, Preston, Lancashire, England, PR1 2HE. Email: sdowne@uclan.ac.uk

\section{Corresponding author:}

Dr Gill Thomson.

Tel: 01772 894578. Email: gthomson@uclan.ac.uk. 


\title{
Emotions and support needs following a distressing birth: Scoping study with pregnant multigravida women in North-West England
}

\begin{abstract}
Objective: To identify the emotional and support needs of pregnant multigravida women who have experienced adverse responses associated with a previous childbirth experience.

Setting: Four maternity hospitals in North-West England.

Design: 100 surveys were distributed at an anomaly scan clinic in each of four maternity hospitals (total $n=400$ ). The survey included an adapted version of a Post-Traumatic Stress Disorder Symptom Scale to explore trauma responses at two broad time points: a) following a previous birth and b) during the current pregnancy. Participants were also asked about the optimal time to receive support post-birth, and the type and provider of support they had accessed/would have liked to access. Descriptive and inferential statistics were undertaken on the quantitative data. The qualitative data was analysed using a basic thematic approach.

Participants: Multigravida pregnant women aged $18+$ years.
\end{abstract}

Findings: The overall response rate was $28 \%(n=112) ; 43 \%(n=46)$ of these had experienced negative/trauma responses associated with a previous birth, $74 \%$ of whom $(n=34)$ continued/reexperienced adverse responses in their current pregnancy. Most commonly reported trauma responses were difficulties in recalling the previous birth(s), avoiding memories associated with it, and the distress associated with these memories when they were recalled. Approximately 54\% $(n=25)$ had received some form of support post-birth, and variations in preferred timing of postnatal support provision were reported. Information on available support and opportunities to discuss the birth with a maternity professional were identified most frequently as preferred support options.

Conclusion \& Implications for Practice: Women's views about what might work should form the basis for effectiveness studies in this area. Among the participants in this study there was evidence of unmet support needs relating to negative or traumatic responses to a previous birth. The range of preferred timing and types of support indicate that flexible needs-based support options should be provided. Further research should assess if these findings are reinforced in a more diverse sample with a higher response rate.

Key words: Traumatic birth, support needs, emotions, PTSD, multigravida, survey 


\section{Introduction}

Perinatal mental health (PMH) is a burgeoning public health issue affecting up to $20 \%$ of women at some point during the perinatal period (Bauer et al, 2014). Post-traumatic stress disorder (PTSD) following childbirth is reported to be a major cause of psychological distress, characterised by hallucinations, intrusive memories, avoidance, and hyper-vigilance (American Psychological Association (APA), 2013). A recent meta-analysis of 78 studies revealed that PTSD rates post-birth were $3.1 \%$ in community samples and $15.7 \%$ in 'at risk' (i.e. experienced previous trauma, history of mental health disorders) women (Grekin and O’Hara, 2014). Psychopathology during pregnancy was also reported to be the highest predictor of PTSD in the community sample (Grekin and O’Hara, 2014). While not all women who experience a traumatic birth will develop PTSD, studies have reported that between 20\% and 48\% experience PTSD symptoms at a sub-diagnostic level (Ayers et al, 2009; Alcorn et al, 2010; Polachek et al, 2012).

There have been recent changes to the Diagnostic and Statistics Manual of Mental Disorders (DSM) criteria for PTSD. The first concerns the event criteria in that while an individual still has had to experience or witness 'actual or threatened death, serious injury or sexual violation' (A1), it no longer requires an individual to respond to an event with intense fear, helplessness and horror (A2) (DSM-V, APA, 2013). Second, the previous DSM-IV criteria specified that individuals had to experience symptoms in three categories (re-experiencing, avoidance and hyperarousal) in order to meet a diagnosis of PTSD. The revised DSM-V has now extended the symptom categories to four by including a negative cognitions and mood domain. The implications of the removal of criterion A2 in the DSM-V has been investigated, with a doubling of the prevalence rate (Boorman et al, 2014). However, as yet the wider implications of these changes in terms of whether they will reduce or decrease PTSD following childbirth is uncertain (McKenzie-Harg et al, 2015).

A history of psychological problems or previous trauma, trait anxiety, obstetric procedures, negative staff-mother interactions, loss of control and lack of partner support are reported to be key risk factors of PTSD following childbirth (Olde et al, 2006; Grekin and O’Hara, 2014). A number of authors also argue that women's subjective interpretations of the birth are the most important pre-disposing factors (Verreault et al, 2012; Garthus-Niegel et al, 2013). A meta-ethnography undertaken by Elmir et al (2010) into women’s experiences and perceptions 
of a traumatic birth highlighted that poor quality care from health professionals was a key contributory factor, especially when it was experienced as degrading. The psychosocial difficulties and consequences of a traumatic/distressing birth include difficulties in motherinfant attachment relationships; a negative impact on social, marital, familial and sexual relationships; lowered emotional wellbeing and self-esteem, as well as classic PTSD responses (Fenech and Thomson, 2014).

Symptoms should continue for more than a one month period in order to qualify for a diagnosis of PTSD (DSM-V, APA, 2013). However, in a childbirth related context, the course and onset of PTSD is unclear. Women may have late presentation of symptoms due to being overwhelmed with having a new baby. The symptoms may also be ascribed to post-natal depression (PND) (Beck, 2011), as the rates of comorbidity between PTSD and PND are high (Stramrood et al, 2011). As women are repeatedly exposed to the reminder of their trauma (i.e. their baby), this could also ameliorate or exacerbate their symptoms (Ayers et al, 2008). Research indicates that PTSD symptoms following childbirth tend to decrease over time (e.g. Ayers and Pickering, 2001). However, longitudinal studies to assess the prevalence of PTSD after six months postnatal are limited (McKenzie-Harg et al, 2015). Women who have experienced a previous traumatic/distressing birth can experience increased fear, stress and anxiety during a subsequent pregnancy (Ballard et al, 1995; Thomson and Downe, 2010), and have an increased likelihood of requesting a caesarean section (Ryding, 2015). As susceptibility for re-trauma and post-partum distress in a subsequent birth has been reported (Beck and Watson, 2010), this raises important, and currently unanswered questions about the potentially long-lasting nature of childbirth related trauma symptoms.

The optimal time to intervene and provide treatment for PTSD following childbirth is a topic of debate, particularly due to concerns that early intervention could pathologise women's normal responses (McKenzie-Harg et al, 2015). Currently there is a lack of good quality research on the effectiveness of treatment interventions, such as cognitive-behaviour or eye movement desensitisation for PTSD following childbirth (McKenzie-Harg et al, 2015). Two randomised controlled trials (RCT) of midwifery-led counselling interventions have been undertaken in Australia. The first involved at-risk women receiving telephone counselling at 72 hours and six weeks postnatal. Trauma and depression symptoms and feelings of self-blame, were reduced when compared to those in the control group (Gamble et al, 2005). The second study involved two telephone sessions of psycho-education provided at 24 and 34 weeks 
gestation to women who had high levels of childbirth fear (Fenwick et al, 2015). While the main outcome of a reduction in caesarean rates was not achieved in this study, women who received the intervention were less likely to experience distressing flashbacks during the postnatal period (Fenwick et al, 2015). Other psycho-social support options reported or suggested to be helpful for pregnant women who had previously experienced a self-defined traumatic birth include an opportunity to review their case notes with a maternity professional, birth partners being involved in co-counselling sessions, opportunities to re-visit the delivery suite and targeted antenatal planning (Kitzinger, 2006; Beck \& Watson, 2010; Thomson \& Downe, 2010). To date, however, there are limited empirical insights into what types of support women themselves would choose to for their trauma related responses, both following the birth and during a subsequent pregnancy.

To provide a baseline for future research in this area, we undertook a scoping survey study with pregnant multigravida women. The survey was designed to explore the nature of women's negative/trauma responses following a previous birth and during the current pregnancy, and the kind of support women themselves would prefer, when they had experienced adverse birth responses.

\section{Methods}

\section{Measures}

A survey was designed with public and patient involvement (PPI). An advert requesting input to the study was posted on a family care research blog at one of the local hospital trusts with a maternity service. Members of the North West Clinical Midwifery Research Network also contributed expert opinion. Overall six mothers and five professionals provided feedback. Requests for language revisions, additional options (i.e. on who should provide support), and question re-ordering were incorporated into the final version. Additionally, the concept of 'blame' was included in the survey tool in line with PTSD DSM-V revisions (APA, 2013).

The final survey tool included the following components:

Initial screening question: The first question asked women to indicate whether they had ever experienced negative emotions/responses associated with a previous birth. Women who 
responded 'no' were directed to the end of the survey, asked to provide demographic information and thanked for their participation.

Women who responded 'yes' were asked to complete, an adapted version of the Post-Traumatic Stress Disorder Symptom Scale (PSS) (Foa et al,1993) twice. Participants were asked to respond using a scale of 0 ('not at all-never') to 3 ('very frequently/extremely so') to 19 statements to record whether the symptom was experienced at two broad time points: a) following the birth and b) currently, i.e. within the last seven days. The included statements represented all symptom classifications of the DSM-V in terms of avoidance (i.e. avoiding memories, thoughts, reminders of the birth, $n=2$ ); re-experiencing (i.e. spontaneous thoughts, flashbacks, nightmares of the event; $n=3$ ); arousal (i.e. aggressive, self-destructive behaviour, hyper-vigilance, $n=5$ ) and negative cognitions and moods (i.e. disrupted memories, sense of blame, isolation from others, low affect, $n=9$ ). Any participants who scored 0 to all of the symptoms were directed to the end of the survey.

In line with the DSM-V diagnostic criteria (APA, 2013), women were asked to indicate whether they had experienced negative/trauma responses for more than a one month period. A free text option to record any additional responses not captured within the revised PSS scale was also included.

Provider and types of support: A pre-defined list of professionals/support networks options (e.g. midwife, obstetrician, health visitor, after birth services, partner/friends/family) was provided for respondents to indicate who had provided support for them, and who they considered was best able to do so. Participants were also invited to record additional networks/professionals they had/or would have preferred to access. A free text question to elicit the 'best time' for mothers to receive support following the birth was also included.

The survey included pre-defined lists of the types of support the mothers received/would have liked to have received both following the index birth and during their current pregnancy. While a number of the pre-defined types of support were included for both time frames assessed (e.g. 'being made aware of support options', 'opportunity to discuss the birth with a professional', 're-visiting the birth environment' and 'homeopathic treatments'), additional types of support were included which differed for the different time frames. For example, following the birth there were additional options of 'access to support groups' and 'further information about negative emotions/experiences following childbirth'. During the current pregnancy, additional 
support options included 'targeted antenatal classes', ‘support writing birth plans' and being allocated to a 'caseload midwifery model' of care. Respondents could also record additional support needs in an open comments box.

Demographic information: Demographic information in relation to age, parity, ethnicity and marital status was recorded.

\section{Participants}

Women were eligible for inclusion if they were pregnant, multiparous, aged 18 years or over, had no known mental health conditions and no known fetal anomalies identified via ultrasound scan.

\section{Data Collection}

Over March - June, 2015 an information pack (an information sheet, survey, support contact details and return paid envelope) was distributed to eligible women at their 18 week anomaly ultrasound scan appointment. This took place on four maternity hospitals in three hospital Trusts in North-West England. Posters were also displayed at the scan clinics, inviting women to contact the research team if they wished to take part. At one of the hospitals the packs were distributed by radiography staff (Trust three), and at the other hospitals they were distributed by research staff/midwives employed at the Trust. Staff were asked to distribute 100 at each clinic/hospital. A total of 400 questionnaires were distributed.

\section{Ethics}

Ethics approval was obtained from a national research ethics committee (14/NW/1476), and from the Science, Technology, Engineering, Medicine and Health (STEMH) ethics subcommittee at the authors University (project no: 316). R\&D governance approvals were granted by the Research and Development departments at each of the participating hospital Trusts. Consent was implicit if the survey was completed and returned. As it was recognised that the survey could elicit distress, the contact details of suitable professionals or services were included in the survey pack.

\section{Analysis}

All completed surveys were entered into SPSS v.22 and analysed using descriptive and inferential statistics. All the narrative text in the open comments boxes were extracted and 
grouped together and then analysed using a simple thematic approach in line with recent publications reporting analyses of narrative comments in quantitative postal questionnaires (Redshaw \& Hockley, 2010; Downe et al, 2012; Redshaw \& Henderson, 2012). All analytical decisions were shared and discussed between the two authors. The qualitative and quantitative findings were then divided into four broad sections: the experience of trauma; who should provide support; when it should be available and what type of support should be provided. In each section, the qualitative and quantitative data are presented together.

\section{Results}

Overall, 112 women completed the survey (response rate 28\%). Six surveys had extensive missing data and were removed from the final analysis (total $n=106$ ). An overview of the number of questionnaires issued at each Trust and response rate is presented in Table 1.

\section{Insert Table 1}

Forty-six (43.4\%) of the women had experienced negative/trauma responses associated with a former birth. The remaining 60 (56.6\%) reported no adverse responses. Demographic details of participants who did/did not experience negative/trauma responses are reported in Table 2.

Those who reported negative/trauma responses were significantly more likely to be older $(\mathrm{M}=32.3, \mathrm{SD}=5.0)$ than those who were not negatively affected $(\mathrm{M}=30.2, \mathrm{SD}=5.6)$ by their birth $(t(99.7)=-2.0, \mathrm{p}<0.05)$. Due to the low cell counts and violations of assumptions, chisquare tests could not be performed on the remaining socio-demographic variables. There was however a higher percentage of women from a White ethnic background who reported negative responses following childbirth.

\section{Insert Table 2}

\section{The experience of trauma}

All of the women who reported distress associated with a former birth $(n=46)$ had experienced at least one of the reported trauma symptoms (range 1-19, $\mathrm{M}=8.3, \mathrm{SD}=4.6$ ). The majority ( $n=34,73.9 \%)$ had also continued to experience, or re-experienced, symptoms during their current pregnancy (range 1-19, $\mathrm{M}=3.8, \mathrm{SD}=4.4$ ). The twelve women who reported no negative 
affect in their current pregnancy had a wide range of PPS scores post-birth (range 1-30, $M=8.8$, $\mathrm{SD}=8.3$ ) and only three $(\mathrm{n}=25 \%)$ had accessed support for their negative emotions.

A total score was also calculated from all responses to the revised PSS scale to provide a proxy assessment of negative affect. The scores ranged from 1-42 post-birth (mean=14.5, SD=10.7) and 0-36 (mean=6.4, SD=8.2) within the last seven days. A paired samples t-test revealed a significant difference $(t(45)=5.86, \mathrm{p}<0.001)$ in that women experienced a higher level of trauma responses following the birth when compared to currently.

The negative/trauma symptoms most frequently reported both following the birth and during their current pregnancy were: ‘distressing thoughts or recollections about the birth' (post-birth $\mathrm{n}=37,80.5 \%$; current pregnancy $\mathrm{n}=24,52.2 \%$ ); 'made efforts to avoid thoughts/feelings associated with the birth' (post-birth $n=27,58.7 \%$; current pregnancy $n=15,32.6 \%$ ); 'had difficulties remembering important aspects about the birth' (post-birth $n=26,56.5 \%$; current pregnancy $n=14,30.4 \%$ ). Following the birth almost $60 \%$ of the respondents had 'blamed others' for the events/result of the birth $(n=27,58.7 \%)$. However, this negative response was less apparent during the current pregnancy $(n=10, n=21.7 \%)$.

In Figure 1 a bar chart represents how many of the women experienced at least one of the symptoms within each of the four DSM-V symptom categories at both broad time points assessed. These data highlight that more women experienced symptoms associated with 'negative cognitions and mood' following the birth, when compared to the other three categories. In general, less women reported these symptoms in a subsequent pregnancy than in the period after the birth of the index baby, with the exception of negative cognitions and mood, in which the opposite trend was apparent.

\section{Insert Figure 1}

Twenty-six (56.5\%) women reported that their symptoms had lasted for more than one month following the birth.

Eighteen women provided narratives in the 'any other comments' section with regard to their negative emotions or feelings following childbirth. Three themes emerged from these comments: poor practices and mistrust; health concerns for the infant; and adverse emotions and responses. 
Poor practices and mistrust.

Comments included issues about women 'not being listened to' by care providers and a lack of relationship with staff. Some of the women directly referred to or described feeling 'let down' by professionals both during the birth and postnatally:

'I felt very let down by the health care professionals that assisted my daughter's birth and in particular with the midwives following the birth' (Participant no. 85)

'After 4 days labour and C-section under general anaesthetic I didn't have the energy to breastfeed but felt very little support from midwives, then felt very guilty not immediately but months after' (Participant no. 66)

One woman also referred to how her maternity care experience had led to her having an 'ongoing distrust of medical practitioners' (Participant no. 28).

Health concerns for the infant

Comments that formed this theme were often associated with maternal or infant health, such as neonatal admissions, and the implications of such on providing care for their infants:

'I had pre-eclampsia so my daughter was born by emergency section at 31 weeks. It was a distressing time as she had to stay in hospital a while so I was up and down with emotions at the time' (Participant no. 52)

'Negative concerns regarding current pregnancy and medication. Worried about how my medication is affecting my baby and feeling like any issues will be my fault' (Participant no. 67)

\section{Adverse emotions and responses}

Most of the narratives in the open comments box could be coded under this theme. Women talked about experiencing 'post-natal depression' and 'extreme anxiety': 
'Cried a lot - very upset - avoided talking/felt like I couldn't talk about the birth - very emotional' (Participant no. 48)

Some referred to 'guilt' in terms of what happened during the birth, and due to their 'failure' to breastfeed:

'My son was in NICU and we had feeding latching problems and felt like a failure. I was very stressed' (Participant no. 109)

Two women also specifically reported 'fear' in terms of what and 'why things happened'. Others expressed concerns about a future birth experience ' $a$ lot of anxiety about it happening again' as well as how it had 'put them off' having further children:

'It initially put me off having any more children. It is only now that my daughter is 6 that I feel confident about doing it again' (Participant no. 107)

A support system that explicitly recognises and addresses these fears, anxieties, and emotions is more likely to meet the direct needs of women.

\section{Who provided/should provide support}

Twenty-five women (54.3\%) had received support for their negative emotions following the birth. Eleven women (23.9\%) who had not received support, wished they had done so. While respondents were asked to record either who they had, or who they wished they had received support from one did not answer either of the questions and six provided responses to both. On reviewing the answers from these six participants, this was often due to the women requesting different types of support. Nine of the respondents (19.6\%) reported that they had not wanted, nor sought, any support post-birth.

In Table 3 we provide an overview of which professionals/support networks women had accessed $(n=25)$. Details of who the respondents felt should provide support $(n=17)$ is also recorded (this includes responses from the 11 women who had no support following the birth but wished they had done so, and the six who had received support, but also requested that additional types of support had been provided). These data highlight that, among those who do access help, more women were likely to turn to their personal networks. Those who had not 
accessed any support, or who felt they had not accessed the right type of support, were more likely to state that their preferred support option would have been a midwifery professional.

\section{Insert Table 3}

Eleven out of the 25 participants who had received support provided comments related to the type of support person they had received support from. All of these comments related to support from professionals.

\section{Medicalisation by staff}

Three complained about how GP’s or health visitors had medicalised their responses through labelling their symptoms as 'depression' or 'anxiety'.

\section{Tailoring professional support effectively}

Four women referred to how the professional based support they received had provided 'explanations', 'reassurance' and helped to alleviate fears during their current pregnancy:

'I have recently spoken to my consultant who has talked through my previous experience and offered reassurance that I would not necessarily experience the same problems again. Explaining why I had problems was very helpful' (Participant no. 104)

Whereas from a counter perspective others perceived this support to be insufficient:

'I did not receive enough emotional support from my midwife. In my subsequent pregnancy I was terrified my baby would die again and always just told "it'll be fine”, (Participant no. 63)

\section{When support should be accessed}

All respondents who had experienced negative/trauma responses were asked to identify the 'best time' to receive support following the birth. Thirty-one (86.1\%) responded to this question and provided diverging responses.

The narrative comments fell into two broad themes: identification of a specific time; and different needs at different times. 
Identification of a specific time

Eleven felt that support 'immediately' or 'straight after the birth' was crucial. Others purported that it should be within the first month $(n=9)$, or within a few months $(n=3)$ in order for a period of adjustment and recovery to have taken place:

'Everyone is different but I feel after a few weeks after the birth as it takes time to adjust to being a new mum'. (Participant no. 92)

Five mothers emphasised how initial as well as ongoing support should be provided, i.e. 'straight after, a few months after (after recovered from caesarean)'. Twelve mothers also considered how support during a subsequent pregnancy was crucial to allay any fears or concerns:

'when I was pregnant again and terrified of having the same experience' (Participant no. 93).

The lack of support at the specific time it was needed, and/or the length of time to wait for support, was raised by four of the respondents.

\section{Different needs at different times}

Two considered the question to be too difficult to answer as 'everyone is different - difficult to put a time frame'. One woman combined a sense of a specific time point when the need was greatest for her within a more general awareness that this may not be the same for everyone:

'Everyone is different but I feel after a few weeks after the birth as it takes time to adjust to being a new mum'. (Participant no. 92)

\section{Types of support that are or could be helpful}

The types of support that women did find helpful, or felt would be helpful at both time points are reported in Table 4. 'Being made aware of available support options' and being provided with 'opportunities to discuss the birth with a professional' were preferred by the largest 
percentages of respondents at both time points. Over $60 \%$ of women also identified how they would like to receive targeted antenatal sessions and be allocated to a caseload midwifery model of care during their subsequent pregnancy.

\section{Insert Table 4}

Only a small number of the women $(n=6)$ provided further qualitative feedback on their support needs. The majority of comments focused on relationships with their lead care-giver, through receiving 'continuity' of care from a 'named midwife', who was 'aware of the physical and emotional stress that the previous [birth] caused'.

\section{Discussion}

Nearly half of the women who completed the survey for this study experienced negative emotions/responses associated with a previous birth. Two thirds of these continued to experience, or re-experienced, negative affect in their current pregnancy. These percentages may not be generalizable, as it is possible that women who experienced these kinds of emotions were more likely to complete a survey with this focus. The low response rate does not allow for an assessment of prevalence rates in any specific population. However, the data do reinforce the fact that some women struggle with the negative emotional consequences of trauma after their birth, and into a subsequent pregnancy. While the number of symptoms experienced decreased over time for this specific group of respondents, over half continued to experience symptoms for more than a month after the birth. The findings highlight that many of these respondents would have taken up the option of talking to a professional, and specifically a midwife about their negative emotions associated with childbirth, and to be made aware of available support options, if these had been available.

This study was not intended to identify the prevalence rates of PTSD following childbirth. Even if it had been, such a prevalence study would have been hampered by the fact that there is no validated scale for PTSD following childbirth that conforms to the recent DSM-V revisions (APA, 2013). The finding that $43 \%$ of our sample experienced trauma related symptoms compares to the $45.5 \%$ rate reported by Alcorn et al (2010). Our study has also provided new insights into the number of women who continue to and/or re-experience childbirth-related distress during a future pregnancy. Furthermore, the finding that more women experienced negative cognitions and emotions following a distressing birth event, and particularly during a 
future conception, contributes to the debate on how the inclusion of this symptom category in the DSM-V will impact on PTSD perinatal rates (McKenzie et al, 2015).

The most common symptoms reported by our respondents reflected a tension in women not being able to recall significant aspects of the birth, trying to avoid birth memories and then experiencing distress when they did. These responses represent three out of the four DSM-V symptom clusters, namely; re-experiencing, avoidance and negative cognitions and mood (APA, 2013). They also signify the difficulties of processing and assimilating memories following a traumatic ordeal. Individuals who experience a traumatic event (birth or otherwise) can often experience retention and forgetting, whereby memories can be spontaneously replayed with vivid clarity or resist integration (van der Kolk \& Fisler, 1995). This is believed to be due to traumatic memories being encoded differently than those from other experiences as a result of altered attentional processes and/or a heightened state of arousal (van der Kolk, 1994).

In our study women appeared to be cognisant of their need to process their birth memories. The majority of respondents reported that they either had or would have found a review and discussion of their birth with a maternity professional to be beneficial. The women who accessed this type of support in the study undertaken by Thomson and Downe (2010) reported the benefits of such. Insights from recent midwifery counselling interventions (Gamble et al, 2005; Gamble \& Creedy, 2007; Fenwick et al, 2015) also provide valuable insights into how a woman-centred, psychosocial based ‘conversation' could be provided. However, the finding that over $40 \%$ of women who reported negative emotions following childbirth did not seek out opportunities to discuss their concerns is somewhat disconcerting. This may be related to mothers feeling unable or unwilling to disclose their negative responses due to fears of stigma and reprisals, as reported by others (Fenech and Thomson, 2014). It may also be associated with women's sense of betrayal and 'mistrust' of professionals, as reflected within other qualitative reports (Allen, 1998; Beck, 2004). These insights thereby suggest a conflict in women's desire to understand what happened to them during the birth and why, and intrinsic barriers to help-seeking behaviours. A recent study by Fonseca et al (2015) identified that only $13.6 \%$ of women who screened positive for perinatal depression accessed support for their emotional-based issues. One of the key barriers related to a lack of knowledge about available support (Fonseca et al, 2015). While the majority of women in our study would have liked to 
have been aware of support options at both broad time points, it also raises issues, as reported by Fonseca et al (2015) of how sensitive strategies to increase women's access should be implemented such as the use of appropriate screening procedures amongst maternity care providers and more innovative solutions to access support (e.g. web based tools). The wide variation in terms of when post-birth support should be provided in our study also indicates, as reported by others (Ayers et al, 2007) that a 'one size fits all' approach to support provision is not necessarily appropriate. Flexible support pathways for women to access support, when the need arises and for as long as they require it, should be provided. Furthermore, in line with the responses, this should include a range of support options to allow for the variability in what might work for certain individuals.

In their narrative comments, respondents raised issues not captured in our modified PSS scale. These included on-going mistrust of professionals, health complications, negative selfinternalisations of guilt and failure, and concerns over future conceptions. Some of these findings are similar to those reported in a recent meta-synthesis to explore the postnatal psychosocial implications of a traumatic birth on women (Fenech \& Thomson, 2014). While further revisions are required for screening and diagnostic tools in line with the DSM-5 revisions, the findings from our study, and also identified by Fenech \& Thomson (2015), indicate a need for a more nuanced questionnaire that addresses the range of negative emotions, behaviours and cognitions that women experience post birth. This tool could serve multiple functions, including the detection of women who may require additional support; framing of discussions with women around areas that they might want support in, what that support might consist of, and when it would best be offered to each individual; and as a basis for further intervention studies.

This study is the first of its kind to be undertaken. It provides new insights into the way in which pregnant women continue to, or re-experience negative emotions associated with a previous birth. It also scopes the nature and variability of women's support needs following the birth and during their current pregnancy. There are, however, a number of limitations which restrict the generalisability of the findings. These include the small sample size; low response rate; the low number of responses from diverse ethnic groups; restriction of the survey to three sites in North-West UK; and the risk of response bias. The fact that the respondents who experienced adverse responses were more likely to be older, may also be indicative of these women being subjected to more 'risk' based practices than their younger counterparts. 
Women's adverse responses post-birth may also, in part, be associated with their relationship with their partners (Fenech \& Thomson, 2014). As women's expectations have been found to be associated with their experiences (Goodman et al, 2014) this should also be addressed in similar studies. The midwifery researchers, compared to the ultrasound staff achieved a higher response rate, and while unsurprising, it does emphasise the benefits of involving trained research staff who have an interest in this area. While this was an exploratory study, limited in scope due to resources, the data is useful as the basis for future larger and more comprehensive studies. Further studies could target diverse areas of the UK, with populations from different socio-demographic profiles, and include follow-up qualitative interviews to explore women's experiences, their support needs and the benefits and limitations of any support they received.

\section{Conclusions}

While this research is a small scale scoping study it identified that many pregnant multigravida women experience negative/trauma related responses associated with childbirth, with these difficulties often continuing, or being re-experienced during a subsequent pregnancy. Women often struggle to assimilate memories of a traumatic birth and experience distress when memories were recalled. The findings suggest that some women do not disclose or discuss their concerns following the birth, with implications for long-term morbidity and susceptibility for re-trauma during a future birth experience. Due to the economic, emotional and social impact of poor mental health on maternal, infant and familial wellbeing, timely support is needed. While further and more comprehensive research is required, the findings suggest that a 'one size fits all' approach to support post-birth is not necessarily appropriate. Flexible needs-based support programmes should be provided, both in terms of availability so that they can be accessed as and when women need them, and in terms of the type of support on offer.

\section{References}

Allen, S., 1998. A qualitative analysis of the process, mediating variables and impact of traumatic childbirth. Journal of Reproductive and Infant Psychology16, 107-131.

Alcorn, K.L., O’Donovan, A., Patrick, J.C., Creedy, D., Devilly, G.J., 2010. A prospective longitudinal study of the prevalence of post-traumatic stress disorder resulting from childbirth events. Psychological Medicine 40, 1849-1859. 
American Psychiatric Association (APA), 2013. Diagnostic and Statistical Manual of Mental Disorders, Fifth Edition. APA, Arlington.

Ayers, S., Pickering, A.D., 2001. Do women get posttraumatic stress disorder as a result of childbirth? A prospective study of incidence. Birth 28(2), 111-118

Ayers, S., McKenzie-McHarg, K., Eagle, A., 2007. Cognitive behaviour therapy for postnatal post-traumatic stress disorder: case studies. Journal of Psychosomatic Obstetrics \& Gynaecology 28(3), 177-184.

Ayers, S., Joseph, S., McKenzie-McHarg, K., Slade, P., Wijma, K., 2008. Post-traumatic stress disorder following childbirth: Current issues and recommendations for research. Journal of Psychosomatic Obstetrics \& Gynaecology 29(4), 240-250.

Ayers, S., Harris, R., Sawyer, A., Parfitt, Y., Ford, E., 2009. Posttraumatic stress disorder after childbirth: Analysis of symptom presentation and sampling. Journal of Affective Disorders 119, 200-204.

Ballard, C.G., Stanley, A.K., Brockington, I.F., 1995. Post-traumatic stress disorder (PTSD) after childbirth. British Journal of Psychiatry 166: 525-528.

Bauer, A. Parsonage, M. Knapp, M. Lemmi, V., Adelaja, B., 2014. The costs of perinatal mental health problems. Centre for Mental Health and London School of Economics, London.

Beck, C.T., 2004. Post-traumatic stress disorder due to childbirth: the aftermath. Nursing Research, 53,216-224.

Beck, C.T., Watson, S., 2010. Subsequent childbirth after a previous traumatic birth. Nursing Research 59, 241-249.

Beck, C.T., 2011. Revealing the subtle differences in postpartum mood and anxiety disorders: phenomenology holds the key. In: Thomson, G., Dykes, F \& Downe, S. 
(Eds.), Qualitative Research in Midwifery and Childbirth: Phenomenological Approaches. Routledge, London. pp. 193-214.

Boorman, R. J., Devilly, G. J., Gamble, J., Creedy, D. K., Fenwick, J., 2014. Childbirth and criteria for traumatic events. Midwifery 30(2), 255-261.

Downe, S., Kingdon, C., Kennedy, R., Norwell, H., McLaughlin, M.J., Heazell, A.E. 2012 Post-mortem examination after stillbirth: views of UK-based practitioners. European Journal of Obstetrics \& Gynecology and Reproductive Biology 162(1), 33-37.

Elmir, R., Schmied, V., Wilkes, L., Jackson, D., 2010. Women's perceptions and experiences of a traumatic birth: A meta-ethnography. Journal of Advanced Nursing 66, 2142-2153.

Fenech, G., Thomson, G., 2014. 'Tormented by Ghosts of their Past': A metasynthesis to explore the psychosocial implications of a traumatic birth on maternal wellbeing. Midwifery 30, 185-193.

Fenech, G., Thomson, G., 2015. Defence against trauma: women’s use of defence mechanisms following childbirth-related trauma. Journal of Reproductive and Infant Psychology 33(3), 268-281.

Fenwick, J., Toothill, J., Gamble, J., Creedy, D.K., Buist, A., Turkstra, E., Sneddon, A., Scuffham, P.A., Ryding, E.L., 2015. Effects of a midwife psycho-education intervention to reduce childbirth fear on women's birth outcomes and postpartum psychological wellbeing. BMC Pregnancy and Childbirth 15:284.

Foa, E.B., Riggs, D.S., Dancu, C.V., Rothbaum, B.O., 1993. Reliability and validity of a brief instrument for assessing post-traumatic stress disorder Journal of Traumatic Stress 6(4), 459-473.

Fonseca, A., Gorayeb, R., Canavarro, M.C., 2015. Women's help-seeking behaviours for depressive symptoms during the perinatal period: Socio-demographic and clinical correlates and perceived barriers to seeking professional help. Midwifery 31(12), 1177-1185. 
Gamble, J.., Creedy, D., Moyle, W., Webster, J., McAllister, M., Dickson, P., 2005.

Effectiveness of a counselling intervention following a traumatic childbirth: A randomized controlled trial. Birth 32(1), 11-19.

Gamble, J., Creedy, D., 2007. A counselling model for postpartum women after distressing birth experiences. Midwifery 25(2), e21-30

Garthus-Niegel, S., von Soest, T., Vollrath, M.E., Eberhard-Gran, M., 2013. The impact of subjective birth experiences on post-traumatic stress symptoms: a longitudinal study. Archives of Women's Mental Health 16(1), 1-10.

Goodman, P., Mackey, M.C., Tavakoli, A.S., 2004. Factors related to childbirth satisfaction. Journal of Advanced Nursing 46(2), 212-219.

Grekin, R., O’Hara, M.W., 2014. Prevalence and risk factors of postpartum posttraumatic stress disorder: a meta-analysis. Clinical Psychology Review 34(5), 389-401.

Kitzinger, S., 2006. Birth Crisis. Routledge Press, London.

McKenzie-McHarg, K., Ayers, S., Ford, E., Horsch, A., Jomeen, J., Sawyer, A., Stramrood, C., Thomson, G., Slade, P., 2015. Post-traumatic stress disorder following childbirth: an update of current issues and recommendations for future research. Journal of Reproductive and Infant Psychology 33(3) 219-237.

Olde, E., van der Harta, O., Klebera, R., van Sona, M., 2006. Posttraumatic stress following childbirth: A review. Clinical Psychology Review 26(1), 1-16.

Polachek, I.S., Harari, L.H., Baum, M., Strous, R.D., 2012. Postpartum post-traumatic stress disorder symptoms: the uninvited birth companion. Israel Medical Association Journal 14(6), 347-53.

Redshaw, M., Hockley, C., 2010. Institutional processes and individual responses: women's experiences of care in relation to cesarean birth. Birth 37(2), 150-159. 
Redshaw, M., Henderson, J., 2012. Learning the hard way: expectations and experiences of infant feeding support. Birth 39(1), 21-29.

Ryding, E.L., Lukasse, M., Parys, A.S., Wangel, A.M., Karro, H., Kristjansdottir, H., Schroll, A.M., Schei, B., 2015. Fear of childbirth and risk of cesarean delivery: a cohort study in six European countries. Birth 42(1), 48-55.

Stramrood, C.A., Paarlberg, K.M., Huis In't Veld, E.M., Berger, L.W., Vingerhoets, A.J.P., van Pampus, M.G., 2011. Posttraumatic stress following childbirth in homelike and hospital settings. Journal of Psychosomatic Obstetrics and Gynaecology 32, 88-97.

Thomson, G., Downe, S., 2010. Changing the future to change the past: women's experiences of a positive birth following a traumatic birth experience. Journal of Reproductive and Infant Psychology 28, 102-112.

van der Kolk, B.A., Fisler, R., 1995. Dissociation and the fragmentary nature of traumatic memories: overview and exploratory study. Journal of Traumatic Stress 8(4), 505-25.

van der Kolk, B.A., 1994. The body keeps the score: Memory and the evolving psychobiology of posttraumatic stress. Harvard Review Psychiatry 1(5), 253-265.

Verreault N, Da Costa D, Marchand A, Ireland K, Banack H, Dritsa M, Khalifé S., 2012. PTSD following childbirth: A prospective study of incidence and risk factors in Canadian women. Journal of Psychosomatic Research 73, 257-263. 
Table 1: Response rate at each Trust

\begin{tabular}{|l|l|l|l|}
\hline Site & Total issued & Total returned & Response rate \\
\hline Trust one & 100 & 21 & $21 \%$ \\
\hline Trust two & 200 & 74 & $37 \%$ \\
\hline Trust three & 100 & 11 & $11 \%$ \\
\hline TOTAL & $\mathbf{4 0 0}$ & $\mathbf{1 0 6}$ & $\mathbf{2 6 . 5 \%}$ \\
\hline
\end{tabular}


Table 2: Demographics of respondents who did/did not experience any negative/trauma responses following childbirth

\begin{tabular}{|c|c|c|c|c|}
\hline & \multicolumn{2}{|c|}{$\begin{array}{l}\text { Did not experience } \\
\text { negative/trauma } \\
\text { responses }(\mathrm{n}=60)\end{array}$} & \multicolumn{2}{|c|}{$\begin{array}{l}\text { Did experience } \\
\text { negative/trauma emotions } \\
(\mathrm{n}=46)\end{array}$} \\
\hline & $\mathrm{N}$ & $\%$ & $\mathrm{~N}$ & $\%$ \\
\hline $\begin{array}{l}\text { Age: } \\
\text { 20-24 years } \\
\text { 25-29 years } \\
\text { 30-34 years } \\
\text { 35-39 years } \\
\text { 40+ years } \\
\text { Not recorded }\end{array}$ & $\begin{array}{r}10 \\
19 \\
19 \\
9 \\
3\end{array}$ & $\begin{array}{r}16.6 \\
31.7 \\
31.7 \\
15.0 \\
5.0\end{array}$ & $\begin{array}{r}3 \\
10 \\
18 \\
10 \\
4 \\
1\end{array}$ & $\begin{array}{l}6.5 \\
21.7 \\
39.1 \\
21.7 \\
8.7 \\
2.2\end{array}$ \\
\hline $\begin{array}{l}\text { Number of previous } \\
\text { children: } \\
0^{1} \\
1 \\
2 \\
3 \\
4+\end{array}$ & $\begin{array}{r}1 \\
38 \\
12 \\
6 \\
3\end{array}$ & $\begin{array}{r}1.7 \\
63.3 \\
20.0 \\
10.0 \\
5.0\end{array}$ & $\begin{array}{r}2 \\
30 \\
11 \\
2 \\
1\end{array}$ & $\begin{array}{r}4.3 \\
65.2 \\
23.9 \\
4.3 \\
2.2\end{array}$ \\
\hline $\begin{array}{l}\text { Ethnicity: } \\
\text { White } \\
\text { Mixed } \\
\text { Asian } \\
\text { Black } \\
\text { Chinese } \\
\text { Not recorded }\end{array}$ & $\begin{array}{r}51 \\
1 \\
5 \\
1 \\
2\end{array}$ & $\begin{array}{r}85.0 \\
1.7 \\
8.3 \\
1.7 \\
3.3\end{array}$ & $\begin{array}{r}44 \\
1\end{array}$ & $\begin{array}{r}95.6 \\
2.2\end{array}$ \\
\hline $\begin{array}{l}\text { Marital status: } \\
\text { Married } \\
\text { Relationship/Living } \\
\text { together } \\
\text { Single } \\
\text { Civil Partnership } \\
\text { Not recorded }\end{array}$ & $\begin{array}{l}28 \\
23\end{array}$ & $\begin{array}{l}46.7 \\
38.3 \\
\\
8.3 \\
1.7 \\
5.0\end{array}$ & $\begin{array}{l}27 \\
17\end{array}$ & $\begin{array}{r}58.7 \\
36.9 \\
\\
2.2 \\
\\
2.2\end{array}$ \\
\hline
\end{tabular}

${ }^{1}$ Mothers who had had a previous stillborn only 
Figure 1: Number of women experiencing one of more of the symptoms within the four DSM-V PTSD categories at the two broad time frames assessed (post-birth and current pregnancy).

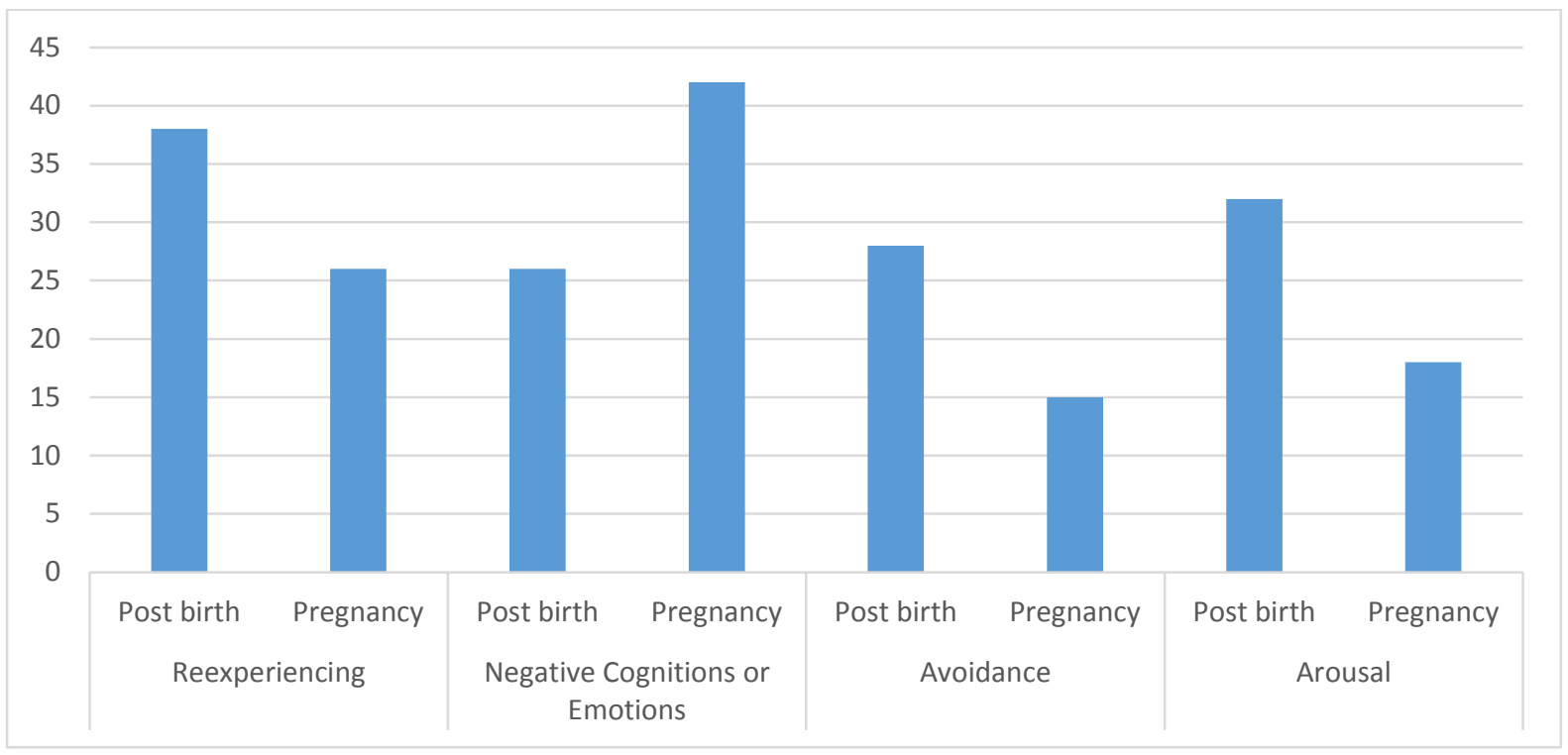


Table 3: Professionals/support networks accessed or would have liked to have accessed post-birth

\begin{tabular}{|c|c|c|c|c|}
\hline \multirow[t]{2}{*}{$\begin{array}{l}\text { Professional/support } \\
\text { networks* }\end{array}$} & \multicolumn{2}{|c|}{$\begin{array}{l}\text { Who respondents talked } \\
\text { to/accessed support from } \\
\text { following the birth } \\
(\mathrm{n}=25)\end{array}$} & \multicolumn{2}{|c|}{$\begin{array}{l}\text { Respondents views on who } \\
\text { should provide support } \\
\text { following the birth }(\mathrm{n}=17)\end{array}$} \\
\hline & $\mathrm{N}$ & $\%$ & $\mathrm{~N}$ & $\%$ \\
\hline $\begin{array}{l}\text { Midwifery } \\
\text { professional }^{1}\end{array}$ & 13 & 52.0 & 15 & 88.2 \\
\hline $\begin{array}{l}\text { Clinical } \\
\text { professional }^{2}\end{array}$ & 9 & 36.0 & 7 & 41.1 \\
\hline Health Visitor & 9 & 36.0 & 7 & 41.1 \\
\hline $\begin{array}{l}\text { Other forms of } \\
\text { formal/peer support }^{3}\end{array}$ & 6 & 24.0 & 10 & 58.8 \\
\hline Partner/Family & 18 & 72.0 & 4 & 23.5 \\
\hline Other $^{4}$ & 1 & 4.0 & - & - \\
\hline
\end{tabular}

* Multiple options could be selected

${ }^{1}$ Includes midwife, consultant midwife, independent midwife

${ }^{2}$ Includes General Practitioners and Obstetricians

${ }^{3}$ Includes counsellor, emotional health team, local support group/other mothers, after birth services

${ }^{4}$ Complaints department at the hospital Trust/GP practice 
Table 4: Types of support that were or could be helpful

\begin{tabular}{|c|c|c|c|c|}
\hline \multirow[t]{3}{*}{ Types of support* } & \multicolumn{2}{|c|}{ Post-birth } & \multicolumn{2}{|c|}{ Current pregnancy } \\
\hline & \multicolumn{2}{|c|}{$\begin{array}{l}\text { Did/would have found } \\
\text { helpful }(\mathrm{n}=46)\end{array}$} & \multicolumn{2}{|c|}{$\begin{array}{l}\text { Would be helpful } \\
\quad(\mathrm{n}=46)\end{array}$} \\
\hline & $\mathrm{N}$ & $\%$ & $\mathrm{~N}$ & $\%$ \\
\hline $\begin{array}{l}\text { Being made aware of } \\
\text { available support options }\end{array}$ & 34 & 73.9 & 37 & 80.4 \\
\hline $\begin{array}{l}\text { Opportunity to discuss the } \\
\text { birth with a professional }\end{array}$ & 33 & 71.7 & 34 & 73.9 \\
\hline $\begin{array}{l}\text { Re-visiting the delivery } \\
\text { suite/operating theatre to } \\
\text { help come to terms with the } \\
\text { birth experience }\end{array}$ & 10 & 21.7 & 16 & 34.8 \\
\hline Access to a support group ${ }^{1}$ & 15 & 32.6 & - & - \\
\hline $\begin{array}{l}\text { Links to online support } \\
\text { groups/information }{ }^{1}\end{array}$ & 14 & 30.4 & - & - \\
\hline $\begin{array}{l}\text { Support for birth partners/ } \\
\text { Inclusion of birth partners in } \\
\text { planning/preparing for the } \\
\text { future birth }\end{array}$ & 17 & 36.9 & 16 & 34.8 \\
\hline $\begin{array}{l}\text { Further information (e.g. } \\
\text { leaflets) about negative } \\
\text { emotions/experiences } \\
\text { following childbirth }^{1}\end{array}$ & 21 & 45.6 & - & - \\
\hline $\begin{array}{l}\text { Specialist support (e.g. } \\
\text { psychological/counselling } \\
\text { based support) }\end{array}$ & 17 & 36.9 & 21 & 45.7 \\
\hline $\begin{array}{l}\text { Homeopathic treatments (to } \\
\text { reduce anxiety, stress, etc) }\end{array}$ & 14 & 30.4 & 15 & 32.6 \\
\hline $\begin{array}{l}\text { Allocated to a caseload (one } \\
\text { to one) midwifery based } \\
\text { care in current pregnancy }^{1}\end{array}$ & - & - & 29 & 63.0 \\
\hline $\begin{array}{l}\text { Targeted antenatal session } \\
\text { to discuss the future birth }\end{array}$ & - & - & 28 & 60.9 \\
\hline $\begin{array}{l}\text { Support with } \\
\text { writing/creating detailed } \\
\text { birth plans }{ }^{1}\end{array}$ & - & - & 16 & 34.8 \\
\hline
\end{tabular}

${ }^{*}$ Multiple options could be selected

${ }^{1}$ Questions asked during post-birth or during current pregnancy 